\title{
Effect of nervous activities on milk flow process in cows
}

\author{
V.T. Golovan, D.V. Osepchuk, D.A. Yurin*
}

Krasnodar Research Centre for Animal Husbandry and Veterinary Medicine, 4 Pervomayskaya Street, Znamensky, Krasnodar, 350055, Russian Federation

*Corresponding author e-mail: 4806144@mail.ru

Journal of Livestock Science (ISSN online 2277-6214) 13: 25-32

Received on 6/9/21; Accepted on 20/12/21; Published on 8/1/22

doi. 10.33259/JLivestSci.2022.25-32

\begin{abstract}
The aim of the research was to study the effect of the type of higher nervous activity on the excretory function of the mammary gland. Cows are classified according to the types of higher nervous activity (HNA): Type I - strong, balanced, mobile; Type II - strong unbalanced; Type III - strong inert; Type IV - weak breaking. Under standard milking conditions, in cows of the I HNA type there were observed: a tendency or a significant increase in single milk yield up to $14.4 \%$ and milking time up to $23.4 \%$ in the morning milking in comparison with other types. The conditioned stimulus "foreign" milkmaid, when applied once or twice, caused an increase in the number of milk flow cycles in I HNA type cows to $43.6 \%$ per lunchtime milking; and in type II, an increase in their number to $113 \%$ with a decrease in the duration of one cycle to $69.6 \%$ both in the morning and lunchtime milking, compared with standard conditions. The following positively correlates with the intensity of milk flow: single milk yield, the milk flow rate for the first and second minutes of milking and maximum, the percentage of milk yield for the first and second minutes, the number of milk production cycles for two, three minutes and in general for milking. Negatively correlates the time of milk yield of the first 50 and $100 \mathrm{~g}$ of milk, the achievement of the maximum rate of milk flow and the total milking time. The process of inhibition of milk flow weakens these connections. The type of HNA in cows affects the relationship of indicators of milk flow both under conditions of varying degrees of readiness for milk flow, and action of conditioned and unconditioned stimuli on the animals used in the experiment.
\end{abstract}

Keywords: milk flow process, milking temperament; behavioral reactivity; dairy cattle; animal welfare 


\section{Introduction}

To predict the productivity of cattle on a farm, not only indicators based on resources, such as housing conditions, availability of feed, water, are important, but also characteristics associated with animals, such as behavior, lack of stress. Studies have been conducted to assess the effect of temperament on the performance, reproductive capacity and health of cows housed in tied-stalls. Research results have shown that the temperament of cows can be used as a trait in animal breeding. There is an economic effect from the use of this trait: calmer cows have significantly higher milk yields, while maintaining the best indicators of physical condition throughout lactation with stall keeping in barns. In addition to increasing milk production, the risk of developing metabolic diseases decreases (Mincu, 2021; Marçal-Pedroza, 2020; Marçal-Pedroza, 2021).

It is noted that excitable cows have smaller size of the follicles and lower concentration of progesterone in the blood plasma is (Vedovatto, 2021). Studies have been carried out to prove the heritability of the temperament of cows, on the basis of which it is possible to select animals (Stephansen, 2018; Hemsworth, 2003).

Studies have been conducted to find out how the type of higher nervous activity affects the behavior, physiology and productivity of dairy cows that are milked in a familiar and new milking environment. The temperament of the cows was determined based on the calculation of the time to leave the stall. The cows were divided into 3 groups. Cows' behavioral responses to humans were assessed using four tests: containment, exit rate, avoidance distance test, and voluntary proximity test. The cows were milked according to established procedures with a carousel milking machine. Behavioral, physiological and performance indicators were collected for five consecutive days. Heart rate, cortisol and oxytocin concentrations, and milk yield were taken into account. The following week, the cows were milked in a new environment with a herringbone milking machine on the same farm for five consecutive days. The data and sample collection program were repeated. The cows were then injected with exogenous adrenocorticotropic hormone (ACTH) to measure adrenal sensitivity. According to the results of these studies, it was found that cows with different temperaments differ in behavioral and physiological responses to milking and work stress (Sutherland, 2012).

One important feature should be emphasized: before milking a cow with a milking machine, it is necessary to induce a milk flow reflex, a derivative of the nervous system. It consists of an afferent arch, including the peripheral nervous system and central parts of the brain (hypothalamus), an efferent arch, and an effector in the form of a mammary gland. As a result, milk flow occurs. This process is long in time (normally from 3 to 8 minutes) and depends on the strength of the initial excitation of the central nervous system. The reflex proceeds under the control of the central nervous system until the possible complete release of the udder from milk, but it can inhibit the reflex by a physiological mechanism. The mechanism of the emergence, course or inhibition of the milk flow reflex, as well as the complete milking of a cow in each milking in a particular situation, certainly depends on the type of higher nervous activity of animals, including the force of excitation and inhibition of the reflex and their balance. And milk productivity per day, month and lactation as a whole consists of single milk yield.

This circumstance increases the role of the excretory function of the mammary gland in the productivity of dairy cows during machine milking, in comparison with manual milking or calf sucking, where there is practically no such problem, since the milk flow process is freely and easily triggered and supported by the calf or the hand of the milkmaid (Kézér, 2015; Wenzel, 2003; Silva, 2017).

The work was carried out for the manifestation and systematization of individual differences in the responses of Black-and-White cows to conditioned and unconditioned stimuli arising in production conditions. Changes in the secretory and excretory functions of the mammary gland were studied in animals under conditions of machine milking.

\section{Material and methods}

The purpose of the research was to study the effect of the type of higher nervous activity on the excretory function of the mammary gland. The experiment was carried out at the Pilot production farm of Krasnodar Research Centre for Animal Husbandry and Veterinary Medicine (45.05646576845831, 39.13705196872246).

The research was carried out on 72 first-calf heifers of the Black-and-White breed. The sample was characterized by the inclusion of all animals in the experiment as they calved. The cows were fed according to zootechnical standards, kept tethered in barns for 200 heads, milked 3 times a day with an interval of 12.6 and 6 hours. The animals were assigned to operators for the entire lactation period. In all cows, the types of higher nervous activity (HNA) were determined by the method of conditioned reflexes to food stimuli.

The experiment was carried out in four periods on first-calf heifers in the 2 nd month of lactation. The first and third periods lasted from 5 to 10 days, the second and fourth - one day each. In the first and third periods, the types of HNA were studied during milking by an "own" milkmaid with an adequate $40 \mathrm{~s}$ preparation of the udder for milking and the standard technology of machine milking. It included washing and wiping the udder with massage, milking the first streams of milk. In the second period, the udder of the cows was prepared by a "foreign" milkmaid for three milking sessions in a row with full preparation of the udder. In the fourth period, the preparation of the udder was incomplete and lasted 10 seconds. It included wiping the udder with a wet towel and sucking off the first streams of milk, followed by a delay with the suspension of the apparatus for $30 \mathrm{~s}$. In the II, III and IV periods of the experiment, the experimenter was present during the registration milking. In everything else, the milking technology did not differ from the standard recommended for the ADM-8 installation, the stall, time, sequence and milking side were kept constant. 
Cows were milked with a Milking machine quaternary (DACH - 1). The time of each $50 \mathrm{~g}$ of milk successively milked from one quarter of the udder was taken into account, then the milking rate was calculated. The numbering of the types of higher nervous activity (HNA) is applied: I type - strong balanced mobile; Type II - strong unbalanced; Type III - strong inert; Type IV - weak braking.

All animal experiments were complied with the appropriate guidelines and approved by the appropriate ethics committee prevailing in the Russia.

\section{Results}

At the beginning of the experiment by the method of conditioned reflexes to food stimuli, the types of HNA were determined in 34 cows. Of these, 9 are classified as type I, 7 as type II, 10 as type III and 8 as type IV. The characteristics of milk flow in cows of I HNA type in the presence of an unauthorized person (an experimenter during milking) are presented in Table 1.

As can be seen from Tables 1 and 2, under standard conditions, cows of the I HNA type, in comparison with other types, have tendencies or a significant increase in single milk yield up to $14.9 \%$ (to types II and IV), milking time - up to $23.4 \%$ (to type II), milk flow rate - up to $15 \%$ (to type IV), the total number of cycles of milk flow rate per milking - up to $35.7 \%$ (to types II and IV), the time interval before the onset of maximum milk flow rate up to $31 \%$ (to II type), the duration of one milk flow cycle up to $65 \%$ (to type IV). In cows of II HNA type in the presence of a stranger, in comparison with cows of I HNA type, there was a reduced level of single milk yield to $14.9 \%$, an increased percentage of milk yield in the first minute at lunchtime to $74.2 \%$, and in the morning and intwo minutes by $62.7 \%$. In the morning, there was a tendency to accelerate the appearance of the milk flow reflex and reduce the total number of milk flow cycles to $29.5 \%$.

In cows of type III of HNA, in comparison with the first type, under the same conditions in the morning and at lunchtime, there were no significant differences in the amount of milk, time and average rate of milking. At the same time, the percentage of milk yield significantly increased in the first two minutes to $63.2 \%$ in the morning and to $13.6 \%$ at lunchtime.

In cows of IV HNA type, in comparison with type I, under standard milking conditions with the presence of an experimenter in the morning and at lunchtime, there was a tendency to decrease the single milk yield to $14.4 \%$, the average milk flow rate to $14.7 \%$. The percentage of milk yield for the first and second minutes of milking in the morning was significantly higher, up to $69.9 \%$, and at lunchtime, only for the first minute of milking - $62 \%$. In the morning and at lunchtime, the milk flow rate for the second and third minutes of milking is significantly lower, as well as the maximum. There is a tendency or a significant decrease in the number of cycles of milk flow rate for three minutes and in general for milking - up to $35.7 \%$ and their duration increases to $65.1 \%$

In the second period of the experiment, when milking by a "foreign" milkmaid, in the morning, the cows of the I HNA type show a strong tendency to increase the percentage of milk yield in the first and second minutes to $42 \%$. During lunchtime milking, the number of cycles of milk flow rate increases for three minutes and, in general, for milking - up to $43.6 \%$ in comparison with the standard technology (Table 3).

In the fourth period of the experiment, the following tendencies appear in cows of I HNA type with inadequate preparation of the udder: in the morning a slight decrease in milk yield to $10.4 \%$, an increase in the time of milking of the first $50 \mathrm{~g}$ of milk and the time for reaching the maximum intensity of milking to $15.4 \%$. At lunchtime, there is a tendency to decrease the average milk flow rate to $11.8 \%$ and the percentage of milk yield in the second minute to 31.2 in comparison with the standard technology (Table 4).

In cows of II HNA type, when milking by a "foreign" milkmaid (in the second period) in the morning and at lunchtime, the number of cycles of milk flow rate significantly increased to $113 \%$ with a decrease in the duration of one cycle to $69.6 \%$ (Table 3 ). Other indicators did not change significantly compared to conventional milking technology.

With the reduction of pre-milking manipulations in the IV period, both in the morning and at lunchtime, milk yield and average rate of milk flow did not change. But the milking time in the morning was $60 \%$ longer, with a decrease in milk flow rate in the second minute. However, in the morning the milk flow rate cycle lasted $70.2 \%$ longer $(\mathrm{P}<0.05)$. At lunchtime, there was a tendency to reduce the amount of milk produced in the first and second minutes to $36.8 \%$, while the intensity of milking in the third minute increased by $58.3 \%$.

In cows of the III HNA type, with a change in the stereotype of milking, compared with standard conditions, no special changes in the function of the mammary gland were observed, except for an increase in the duration of the cycle of milk flow rate with inadequate preparation of the udder by $61.1 \%$ in morning milking (Table 4).

In cows of IV type of HNA, when milking by a "foreign" milkmaid in the second period, there were no significant changes in milk yield compared to standard milking (Table 3). With inadequate preparation of the udder in the fourth period, there were the following tendencies: in the morning the intensity of milking accelerated by $25.8 \%$ in the third minute, and at lunchtime, on the contrary, it slightly slowed down in the second minute of milking to $38.0 \%$. Further in the afternoon there was a significant decrease in the intensity of milking and the percentage of milk yield in the second minute to $37.3 \%$. But the intensity of milking in the third minute of milking increased to $87.4 \%$.

Comparison of the I type of HNA with all the others shows that the differences between them, identified under standard conditions, generally remain in the II and IV periods. The results of the study of the correlation between milk yield and milk flow indicators are presented in Table 5. It can be seen from the table that in cows of type I of HNA under standard milking conditions in the first period there is a strong direct correlation of milk yield in the morning and 
Table 1 - Excretory function of the mammary gland in cows of I HNA type in the morning and lunch milking, $\mathrm{M} \pm \mathrm{m}$

\begin{tabular}{|c|c|c|}
\hline \multirow{4}{*}{ Indicator } & \multicolumn{2}{|c|}{ I HNA type } \\
\hline & \multicolumn{2}{|c|}{ Milking } \\
\hline & M & $\mathrm{L}$ \\
\hline & $\mathrm{M} \pm \mathrm{m}$ & $\mathrm{M} \pm \mathrm{m}$ \\
\hline single milk yield, $\mathrm{kg}$ & $9.2 \pm 0.5$ & $5.2 \pm 0.4$ \\
\hline \multicolumn{3}{|c|}{ Milk flow rate } \\
\hline average, $\mathrm{kg} / \mathrm{min}$ & $1.6 \pm 0.1$ & $1.5 \pm 0.1$ \\
\hline A quarter: for 1 minute, $\mathrm{kg} / \mathrm{min}$ & $0.3 \pm 0.1$ & $0.4 \pm 0.1$ \\
\hline for 2 minutes, $\mathrm{kg} / \mathrm{min}$ & $0.4 \pm 0.1$ & $0.4 \pm 0.1$ \\
\hline for 3 minutes, $\mathrm{kg} / \mathrm{min}$ & $0.4 \pm 0.05$ & $0.2 \pm 0.05$ \\
\hline maximum, $\mathrm{kg} / \mathrm{min}$ & $0.5 \pm 0.1$ & $0.4 \pm 0.06$ \\
\hline \multicolumn{3}{|c|}{ Milk yield percentage for } \\
\hline 1 minute, $\%$ & $16.2 \pm 3.6$ & $30.5 \pm 3.8$ \\
\hline 2 minutes, $\%$ & $36.3 \pm 7.2$ & $67.8 \pm 6.3$ \\
\hline \multicolumn{3}{|c|}{ Milking time } \\
\hline first $50 \mathrm{~g}$ of milk, $\mathrm{s}$ & $97.1 \pm 13.1$ & $80.1 \pm 3.6$ \\
\hline first $100 \mathrm{~g}$ of milk, $\mathrm{s}$ & $104.9 \pm 13.5$ & $89.9 \pm 4.6$ \\
\hline before maximum milk flow rate, $\mathrm{s}$ & $159.1 \pm 27.8$ & $127.0 \pm 20.9$ \\
\hline total, s & $365.4 \pm 30.6$ & $219.6 \pm 15.0$ \\
\hline \multicolumn{3}{|c|}{ Number of milk flow cycles } \\
\hline for 2 minutes & $3.2 \pm 0.7$ & $3.3 \pm 0.06$ \\
\hline for 3 minutes & $5.4 \pm 0.7$ & $4.9 \pm 0.4$ \\
\hline Total & $7.4 \pm 0.8$ & $4.7 \pm 0.6$ \\
\hline Duration of one cycle, $s$ & $0.6 \pm 0.1$ & $0.7 \pm 0.2$ \\
\hline
\end{tabular}

Notes: milking: M - morning, L - lunchtime

Table 2- Excretory function of the mammary gland in cows of II, III and IV types of HNA, $\pm \%$ of changes to I HNA type

\begin{tabular}{|c|c|c|c|c|c|c|}
\hline \multirow[t]{3}{*}{ Indicator } & \multicolumn{6}{|c|}{ HNA type } \\
\hline & \multicolumn{2}{|c|}{ II } & \multicolumn{2}{|c|}{ III } & \multicolumn{2}{|c|}{ IV } \\
\hline & $\mathrm{M}$ & $\mathrm{L}$ & $\mathrm{M}$ & $\mathrm{L}$ & $\mathrm{M}$ & $\mathrm{L}$ \\
\hline single milk yield & $-14.9 *$ & -8.1 & -4.7 & +0.3 & -14.4 & -11.1 \\
\hline \multicolumn{7}{|c|}{ Milk flow tate } \\
\hline average & +9.3 & -5.7 & +5.7 & +7.8 & -10.1 & -14.7 \\
\hline A quarter: for 1 minute & +47.4 & -6.0 & +32.8 & -19.7 & -0.10 & -1.1 \\
\hline for 2 minutes & +14.3 & -42.3 & +44.7 & +7.5 & -17.8 & $-51.3 *$ \\
\hline for 3 minutes & -18.0 & -41.8 & +1.0 & -2.0 & -38.3 & -49.7 \\
\hline maximum & -0.56 & -13.1 & +17.6 & +2.0 & -30.1 & -58.3 \\
\hline \multicolumn{7}{|c|}{ Milk yield percentage for } \\
\hline 1 minute & +64.7 & $+74.2^{*}$ & +56.6 & +3.3 & +69.9 & $+62.0 *$ \\
\hline 2 minutes & +62.7 & +19.9 & +63.2 & +13.6 & +66.1 & +11.9 \\
\hline \multicolumn{7}{|c|}{ Milking time } \\
\hline first $50 \mathrm{~g}$ & -14.1 & -2.8 & -15.4 & -3.0 & -9.8 & +2.9 \\
\hline first $100 \mathrm{~g}$ & -13.9 & -6.6 & -17.1 & -0.3 & -5.9 & +0.4 \\
\hline before max.milk flow rate & -31.0 & -4.5 & -19.9 & -13.1 & -27.0 & -11.9 \\
\hline total & $-23.4 *$ & -2.4 & -10.8 & +7.1 & -8.9 & +2.8 \\
\hline \multicolumn{7}{|c|}{ Milk flow cycles } \\
\hline for 2 minutes & +0.5 & -0.7 & +2.0 & -0.2 & +0.3 & -0.9 \\
\hline for 3 minutes & -2.9 & -38.4 & +24.5 & +24.8 & -20.4 & $-30.7 *$ \\
\hline Total & -19.3 & -29.5 & +0.8 & -12.1 & -23.2 & $-35.7 *$ \\
\hline Duration of one cycle & -5.9 & +43.5 & -22.1 & +34.7 & +45.4 & +65.1 \\
\hline
\end{tabular}

Notes: 1) milking: $\mathrm{M}$ - morning, L - lunchtime, 2) differences with I HNA type: $* \mathrm{P}<0.05, * *-\mathrm{P}<0.01$. 
Table 3 - Influence of the "foreign" milkmaid stimulus on the excretory function of the mammary gland of cows of various types of HNA in the second period, $\pm \%$ change to the standard preparation of the udder

\begin{tabular}{|c|c|c|c|c|c|c|c|c|}
\hline \multirow[t]{4}{*}{ Indicators } & \multicolumn{8}{|c|}{ Type of HNA } \\
\hline & \multicolumn{2}{|c|}{$\mathrm{I}$} & \multicolumn{2}{|r|}{ II } & \multicolumn{2}{|c|}{ III } & \multicolumn{2}{|c|}{ IV } \\
\hline & \multicolumn{8}{|c|}{ Milking } \\
\hline & $\mathrm{M}$ & $\mathrm{L}$ & $\mathrm{M}$ & $\mathrm{L}$ & $\mathrm{M}$ & $\mathrm{L}$ & $\mathrm{M}$ & $\mathrm{L}$ \\
\hline Single milk yield, $\mathrm{kg}$ & -6.2 & -2.2 & -0.26 & -4.8 & +6.8 & +7.3 & -4.8 & -8.9 \\
\hline \multicolumn{9}{|c|}{ Milk flow rate of the quarter } \\
\hline average & -3.8 & -1.8 & -6.4 & +6.6 & +3.6 & +8.3 & -9.2 & -5.7 \\
\hline $1^{\text {st }}$ minute & +8.8 & +7.2 & +5.3 & +6.1 & -4.5 & +14.4 & -3.0 & +5.8 \\
\hline $2^{\text {nd }}$ minute & +9.8 & +3.8 & +10.6 & +13.0 & -8.4 & +9.3 & -7.7 & +1.5 \\
\hline $3^{\text {rd }}$ minute & +12.8 & +4.9 & +6.3 & -8.3 & +22.6 & -25.4 & +24.7 & +9.8 \\
\hline maximum & -3.8 & +2.3 & +30.2 & +35.9 & +7.9 & +24.4 & - & 0 \\
\hline \multicolumn{9}{|c|}{ Milk yield percentage } \\
\hline first minute & +42.2 & +24.1 & +3.5 & -16.5 & -9.7 & -4.7 & +32.0 & +10.3 \\
\hline second minute & +39.8 & +7.7 & +4.9 & -4.6 & -12.1 & -1.2 & +1.7 & +14.2 \\
\hline \multicolumn{9}{|c|}{ Milking time, $\min$} \\
\hline first $50 \mathrm{~g}$ of milk & +20.1 & -5.9 & -11.1 & +0.4 & -10.4 & +9.8 & -7.6 & -2.3 \\
\hline before max. milk flow rate & +29.8 & -21.5 & -26.6 & +31.5 & -9.9 & +19.6 & +6.5 & 0 \\
\hline total & -6.6 & -0.6 & +7.7 & -10.1 & +5.9 & +0.3 & - & -5.0 \\
\hline \multicolumn{9}{|c|}{ Milk flow cycles } \\
\hline For 3 minutes & -4.4 & $+43.6^{*}$ & +4.0 & - & +3.2 & +36.3 & - & 0 \\
\hline total & -11.3 & +23.2 & $+41.7 * *$ & $+113.1 * *$ & +6.7 & 0 & - & 0 \\
\hline Duration of one cycle & +26.3 & -28.6 & $-31.6^{*}$ & $-69.6 *$ & +42.1 & -17.8 & - & 0 \\
\hline
\end{tabular}

Notes: 1) milking: M - morning, L - lunchtime, 2) differences with I HNA type: * - P <0.05, ** - P <0.01.

Table 4 - Influence of the stimulus "inadequate preparation of the udder for milking" on the excretory function of the mammary gland of cows of various types of HNA in the 4th period, $\pm \%$ change with adequate preparation of the udder.

\begin{tabular}{|c|c|c|c|c|c|c|c|c|}
\hline \multirow[t]{4}{*}{ Indicator } & \multicolumn{8}{|c|}{ Type of HNA } \\
\hline & \multicolumn{2}{|c|}{ I } & \multicolumn{2}{|c|}{ II } & \multicolumn{2}{|c|}{ III } & \multicolumn{2}{|c|}{ IV } \\
\hline & \multicolumn{8}{|c|}{ Milking } \\
\hline & $\mathrm{M}$ & $\mathrm{L}$ & $\mathrm{M}$ & $\mathrm{L}$ & $\mathrm{M}$ & $\mathrm{L}$ & $\mathrm{M}$ & $\mathrm{L}$ \\
\hline Single milk yield, kg & -10.4 & -4.4 & -0.9 & -8.6 & -5.7 & -3.3 & +6.9 & +1.3 \\
\hline \multicolumn{9}{|c|}{ Milk flow rate } \\
\hline Quarter: average & -1.8 & -11.8 & -2.3 & +6.6 & +3.6 & +9.8 & -3.5 & -4.1 \\
\hline $2^{\text {nd }} \min$ & -2.9 & -22.9 & -15.8 & -39.4 & -4.5 & +17.9 & +6.0 & $-38.0 *$ \\
\hline $3^{\text {rd }} \min$ & +14.6 & -2.5 & -25.5 & +58.3 & -5.0 & -4.7 & +25.8 & $+87.4^{*}$ \\
\hline maximum & +15.4 & +34.5 & $-31.3 *$ & $+8.7 *$ & -5.0 & -15.2 & +20.6 & +19.6 \\
\hline \multicolumn{9}{|c|}{ Milk yield percentage } \\
\hline $1^{\mathrm{st}} \min$ & -1.9 & +2.3 & -26.4 & -15.4 & -7.9 & +11.1 & +19.9 & +21.6 \\
\hline $2^{\text {nd }} \min$ & +17.1 & -31.2 & +10.5 & $-36.8^{*}$ & -0.1 & +10.5 & +8.8 & $-37.3^{*}$ \\
\hline \multicolumn{9}{|c|}{ Milking time, min } \\
\hline first $50 \mathrm{~g}$ of milk & +18.6 & -17.5 & +2.9 & -13.9 & +1.9 & -3.4 & +5.1 & +7.0 \\
\hline Before max.milk flow rate & -20.4 & +8.3 & -8.1 & +0.6 & -5.6 & -2.4 & -19.0 & +13.3 \\
\hline total & -29.9 & -4.6 & $+60.0^{*}$ & -0.5 & -17.5 & -6.9 & -24.7 & -7.7 \\
\hline \multicolumn{9}{|c|}{ Milk flow cycles } \\
\hline for $2 \mathrm{~min}$ & -5.1 & +8.5 & $+32.0 *$ & -4.2 & +2.6 & -11.2 & +14.1 & +5.1 \\
\hline for $3 \mathrm{~min}$ & -5.5 & -4.3 & -11.7 & - & -11.5 & +13.1 & -4.8 & +66.7 \\
\hline total & -7.9 & - & -5.5 & -17.3 & -17.3 & +2.0 & -19.8 & -21.0 \\
\hline Duration of 1 cycle, $s$ & +21.3 & +7.1 & $+70.2 *$ & +7.8 & $+61.1^{*}$ & -28.3 & +7.9 & -23.9 \\
\hline
\end{tabular}


Table 5 - Correlation of milk yield (1 sign) with indicators of milk flow in cows of different types of HNA with a standard stereotype of milking, "r"

\begin{tabular}{|c|c|c|c|c|c|c|c|c|}
\hline \multirow[t]{4}{*}{ Imdicator } & \multicolumn{8}{|c|}{ Type of HNA } \\
\hline & \multicolumn{2}{|c|}{ I } & \multicolumn{2}{|c|}{ II } & \multicolumn{2}{|c|}{ III } & \multicolumn{2}{|c|}{ IV } \\
\hline & \multicolumn{8}{|c|}{ Milking } \\
\hline & $\mathrm{y}$ & $\mathrm{O}$ & $\mathrm{y}$ & $\mathrm{O}$ & $\mathrm{y}$ & $\mathrm{O}$ & $\mathrm{y}$ & $\mathrm{O}$ \\
\hline Milking time & +0.2 & +0.5 & +0.2 & $+0.7 *$ & +0.1 & $+0.5^{*}$ & +0.4 & +0.5 \\
\hline \multicolumn{9}{|c|}{ Milk flow rate } \\
\hline average & $+0.6^{*}$ & $+0.9^{* *}$ & +0.5 & $+0.7 *$ & +0.5 & $+0.6^{*}$ & +0.56 & +0.3 \\
\hline quarter: $1^{\text {st }} \min$ & $+0.7 *$ & $+0.8^{* *}$ & +0.2 & +0.2 & +0.5 & +0.4 & +0.5 & $+0.6^{*}$ \\
\hline $2^{\text {nd }} \min$ & $+0.7 *$ & $+0.7 *$ & $+0.7 *$ & $+0.8^{* *}$ & $+0.6^{*}$ & $+0.6^{*}$ & $+0.7 *$ & $+0.8 * *$ \\
\hline $3^{\text {rd }} \min$ & +0.4 & -0.4 & $+0.9 * *$ & +0.8 & +0.5 & $+0.8 * *$ & +0.4 & +0.1 \\
\hline maximum & $+0.7 *$ & $+0.8^{* *}$ & +0.6 & $+0.7 *$ & +0.5 & $+0.7 *$ & $+0.7 *$ & $+0.7 *$ \\
\hline \multicolumn{9}{|c|}{ Milk yield percentage } \\
\hline $1^{\text {st }} \min$ & $0.6^{*}$ & +0.4 & -0.3 & $-0.7 *$ & -0.1 & -0.5 & +0.1 & -0.3 \\
\hline $2^{\text {nd }} \min$ & $0.6^{*}$ & +0.06 & -0.2 & -0.6 & -0.1 & -0.5 & 0 & +0.06 \\
\hline Milking time of first $50 \mathrm{~g}$ of milk, min & $-0.8 * *$ & $-0.7^{*}$ & -0.05 & +0.2 & $-0.6^{*}$ & -0.2 & -0.4 & -0.9 \\
\hline \multicolumn{9}{|c|}{ Number of milk flow cycles } \\
\hline for $3 \mathrm{~min}$ & $+0.7 * *$ & $+0.7 *$ & +0.6 & -0.03 & +0.5 & +0.6 & +0.6 & $+0.9 * *$ \\
\hline total & $+0.9 * *$ & $+0.8^{* *}$ & +0.6 & $+0.7 *$ & +0.4 & $+0.9 * *$ & $+0.7 *$ & $+0.7 * *$ \\
\hline Duration of 1 milk flow cycle, $s$ & +0.1 & $-0.7 *$ & -0.3 & -0.2 & +0.2 & -0.4 & $-0.7^{*}$ & $-0.6^{*}$ \\
\hline
\end{tabular}

Table 6 - Correlation of the average intensity of lactation (1 sign) with other indicators in cows of different types of IRR with a standard stereotype of milking, "r"

\begin{tabular}{|c|c|c|c|c|c|c|c|c|}
\hline \multirow[t]{4}{*}{ Indicator } & \multicolumn{8}{|c|}{ Type of HNA } \\
\hline & \multicolumn{2}{|c|}{$\mathrm{I}$} & \multicolumn{2}{|c|}{ II } & \multicolumn{2}{|c|}{ III } & \multicolumn{2}{|c|}{ IV } \\
\hline & \multicolumn{8}{|c|}{ Milking } \\
\hline & $\mathrm{M}$ & $\mathrm{L}$ & $\mathrm{M}$ & $\mathrm{L}$ & $\mathrm{M}$ & $\mathrm{L}$ & $\mathrm{M}$ & $\mathrm{L}$ \\
\hline \multicolumn{9}{|c|}{ Milk flow rate of the quarter: } \\
\hline $1^{\mathrm{st}} \min$ & $0.9 * *$ & $0.9 * *$ & -0.06 & $0.8 * *$ & $0.9 * *$ & $0.8^{* *}$ & $0.9 * *$ & 0.5 \\
\hline $2^{\text {nd }} \min$ & $0.9 * *$ & $0.8 * *$ & $0.9 * *$ & $0.8 * *$ & $0.9 * *$ & $0.9 * *$ & $0.8^{* *}$ & 0.2 \\
\hline $3^{\text {rd }} \min$ & 0.3 & $-0.7 * *$ & 0.5 & 0.2 & 0.4 & $0.8^{*}$ & 0.4 & -0.4 \\
\hline maximum & $0.9 * *$ & $0.9^{* *}$ & $0.8 * *$ & $1.0 * *$ & $0.9 * *$ & $0.9 * *$ & $1.0 * *$ & -0.5 \\
\hline \multicolumn{9}{|c|}{ Milk yield percentage } \\
\hline $1^{\text {st }} \min$ & $1.0^{* *}$ & $0.7 * *$ & 0.5 & -0.04 & $0.7 * *$ & 0.06 & 0.6 & 0.4 \\
\hline $2^{\text {nd }} \min$ & $1.0 * *$ & 0.4 & $0.6^{*}$ & -0.1 & $0.7 * *$ & 0.4 & 0.5 & 0.3 \\
\hline \multicolumn{9}{|c|}{ Milking time, $\min$} \\
\hline First $50 \mathrm{~g}$ of milk & $-0.7 * *$ & -0.5 & $-0.9 * *$ & -0.5 & -0.5 & $-0.7 * *$ & -0.6 & $-0.6^{*}$ \\
\hline $\begin{array}{l}\text { reaching the maximum } \\
\text { milk flow rate }\end{array}$ & -0.3 & -0.3 & -0.01 & 0.1 & -0.1 & 0.1 & -0.6 & -0.3 \\
\hline \multicolumn{9}{|c|}{ Number of milk flow cycles } \\
\hline for $3 \mathrm{~min}$ & $0.9 * *$ & $0.8 * *$ & 0.5 & 0.5 & $0.7 *$ & $0.9 * *$ & 0.8 & 0.2 \\
\hline total & $0.6^{*}$ & $0.8 * *$ & 0.1 & 0.4 & 0.2 & $0.6^{*}$ & 0.4 & 0.3 \\
\hline $\begin{array}{l}\text { Average duration of } 1 \\
\text { milk flow cycle, s }\end{array}$ & -0.3 & -0.5 & 0.4 & -0.3 & -0.1 & $-0.6^{*}$ & $-0.7 *$ & -0.1 \\
\hline Milking time,. $\min$ & $-0.6^{*}$ & 0.01 & -0.7 * & -0.06 & $-0.8^{*}$ & -0.3 & -0.4 & -0.1 \\
\hline
\end{tabular}

at lunchtime (1 trait) with the average and maximum milk flow rate in the first two minutes, as well as with the number of cycles of milk flow rate both in the first three minutes, and in total on average (" $r$ " from +0.6 to +0.9 ). On the contrary, in the morning and at lunchtime there is a strong negative correlation of milk yield with the time of milk yield of the first 50 and $100 \mathrm{~g}$ of milk ("r" = - $0.6-0.9$ ); and at lunchtime there is also a negative correlation with the average duration of milk flow cycles ("r" -0.7).

In cows of type I of HNA in the first period in the morning and at lunchtime, the average rate of milk flow (1 trait) correlates directly, strongly and reliably with the intensity of lactation in the first and second minutes of milking and with the maximum, as well as with the percentage of milk yield in one and two minutes; with the number of milk production cycles in the first three minutes and in general for milking (" $r "=$ from +0.6 to +0.9$)$. A negative relationship between the intensity of milking is manifested with the time of milk production of the first $50 \mathrm{~g}$ of milk and the total time of milking (Table 6). And this is quite understandable, since the shorter the milk yield time of $50 \mathrm{~g}$, the faster the hormonal phase of the milk flow reflex sets in.

Thus, in cows of I HNA type, all the main reflex indicators taken into account correlate equally with milk yield and milk flow rate. Milk yield and milk flow rate also correlate directly and strongly with each other, both in the morning and at lunchtime. In cows of type I of HNA, the correlation of milking time with other indicators of milk yield significantly differs in the morning and lunchtime milking. So, in the morning, milking time negatively correlates with 
the average intensity of milking, the percentage of milk yield in the first and second minutes of milking, positively with the average duration of one cycle. In lunchtime milking, the duration of milking positively correlates with the milk low rate in the third minute of milking and the time to reach the maximum milk flow rate, and negatively - with the time of milk yield of the first 50 and $100 \mathrm{~g}$ of milk, the percentage of milk yield in two minutes, the number of cycles of milk flow rate in two minutes, the number of cycles of milk flow rate in three minutes and its average duration.

In cows of type II of HNA, with a standard stereotype of milking in the first period in the morning, a strong positive correlation of milk yield with the rate of milk flow in the second and third minutes ("r" up to +0.9 ) appears. In lunchtime milking, there is a negative correlation of milk yield with the percentage of milk yield in the first and second minutes of milking and a positive correlation with the maximum and average rate of milk flow, as well as with the total number of milk flow cycles (Table 5).

In the first period, the average rate of milk flow in the morning is inversely correlated with milking time; in the morning and at lunchtime, it directly correlates with the amount of milk milked in the second minute and the maximum rate of milk flow; it correlates inversely with the milking time of the first $50 \mathrm{~g}$ of milk in the morning. In addition, in the morning, a positive relationship is also manifested with the percentage of milk yield in two minutes.

In cows of type II of HNA under standard conditions, compared with type I of HNA, there is no inverse correlation of milk yield with the time of milk yield of the first $50 \mathrm{~g}$ of milk and the percentage of milk yield in the first and second minutes; but there is a correlation of the average milk flow rate with the percentage of milk yield in the first minute of milking and the total number of cycles of milk flow intensity.

In cows of type III of HNA under standard conditions in the morning and at lunchtime, the direction of correlations between milk yield and the studied parameters of milk yield is generally the same as in type I, but somewhat weaker. And at lunchtime, the positive relationship between milk yield and the percentage of milk yield in the first two minutes is completely lost in comparison with type I. In addition, during lunchtime milking, a direct reliable relationship appears between milk yield and the amount of milk milked in the third minute of milking.

Under standard conditions, the relationship between the rate of milk flow and the studied indicators in the morning and at lunchtime is mainly unidirectional with type I, except for its loss with the percentage of milk yield in the first minute of milking at lunchtime.

In cows of IV HNA type under standard conditions, there is a weakening of the positive correlative relationship between the lunchtime milk yield and the average milk flow rate, and in the morning milking, there is the manifestation of a negative correlation with the average time of milk flow rate cycle in comparison with the Ist type (Table 5). In cows of type IV under standard conditions in the morning milking, a decrease in the positive relationship between the average milk flow rate and the percentage of milk yield in the first and second minutes of milking is found, but there is an increase in the negative relationship with the average duration of the milk cycle ("r" $=-0.7)$ compared to I type of HNA. At lunchtime milking with an average intensity of milking, only a negative reliable correlation of the time of milk yield of the first $50 \mathrm{~g}$ of milk remains (Table 6).

Based on the experiment, it was shown that the intensity of milking directly correlates with the strength of the milk flow reflex, the amount and cyclicity of oxytocin intake. That is, with the stimulation and maintenance of the reflex flow at a high level. On the example of cows of type I of HNA, it can be seen that an increase in the intensity of milking in the first and second minutes, average and maximum, the percentage of milk yield in the first and second minutes, the number of cycles of the intensity of milk production in two, three minutes and in general for milking, as well as a decrease in the time of milkimf of the first $50 \mathrm{~g}$ of milk and the achievement of the maximum milk flow rate, the average duration of the milk flow rate cycle as a whole means a strong process of arousal of the milk flow reflex. At the same time, the cycles of milk flow rate introduced by us can show the nature of secretion and release of oxytocin into the blood.

The reverse change in the listed indicators means inhibition of the milk flow reflex. Differences in these correlations between the types of HNA show the features of their nervous system, which are reflected in the processes of excitation and inhibition in terms of their strength, balance and mobility. The weakening of correlations between milk yield in cows of the Ist HNA type with indicators of milk yield in case of inadequate preparation of the udder, compared with he adequate, in the morning milking indicates a significant role of this stimulus in conditions of "maximum" filling of the mammary gland. However, the manifestation of this stimulus during lunchtime milking weakens, which indicates an increase in the role of internal factors that determine milk flow in the process of machine milking.

In cows of I HNA type in conditions of a sharp reduction in afferent impulses to trigger the reflex of milk flow in the fourth period of the experiment, with a strong filling of the mammary gland and high readiness for milk flow, the relationship between the milk yield and the amount of milk produced in the first and second minutes of milking, and the milk flow rate in the first minute is lost. These relationships are carried over to the subsequent stages of the reflex, which has a positive effect on the maintaining of the average indicators characterizing milk flow. At lunchtime milking (against the background of a decrease in readiness for milk flow), a decrease in afferent impulses to trigger a reflex had an insignificant effect on the relationship between milk yield and milk flow rates. They have almost remained the same as with the standard milking stereotype. With inadequate preparation of the udder for milking, despite the disorder in the initial stage of the milk flow reflex, the average rate of milk flow remains due to other indicators of milk flow, although in a somewhat weakened form. 
In cows of II HNA type, a change in the stereotype of milking due to a strong arousal process influenced the function of the mammary gland to a lesser extent. In cows of III HNA type, the conditioned stimulus "foreign" milkmaid is realized in the form of an increase in the frequency of milk flow cycles. In these animals, the onset of the milk flow reflex is of great importance. Its delay is not sufficiently compensated for in the future and leads to a decrease in the intensity of milking, an increase in the milking time. Cows of IV HNA type show the weakest correlative relationship between the milk flow rate with other indicators in conditions of lunchtime milking, in comparison with other types, which emphasizes the weakness of the arousal process.

\section{Discussion}

Under standard milking conditions in cows of I HNA type there was observed a tendency or a significant increase in single milk yield up to $14.4 \%$ and milking time up to $23.4 \%$ in the morning milking in comparison with other types. Under these conditions, cows of II and IV type differed from cows of I HNA type in a reduced single milk yield to $14.9 \%$ and a strong tendency to reduce the intensity of milking to $14.7 \%$.

The conditioned stimulus "foreign" milkmaid, when applied once or twice, caused an increase in the number of milk flow cycles in type I HNA cows to $43.6 \%$ per lunchtime milking; and in type II, an increase in their number to $113 \%$ with a decrease in the duration of one cycle to $69.6 \%$ in both the morning and lunchtime milking, compared with standard conditions. But this stimulus is not effective enough to detect changes in milk flow in other types of HNA.

An unconditioned stimulus "inadequate" preparation of the udder for milking with one or two applications caused signs of impaired milk flow in all cows. At the same time, in animals of II and III types of HNA the average duration of one milk flow cycle increased by 70.2-61.1\%, respectively, in morning milking, and a tendency or significant decrease in the percentage of milk yield in the first minute of milking in cows of types I, II and IV appeared. up to 37.3\% at lunchtime milking, compared to standard conditions (Marçal-Pedroza et al., 2020; Mincu et al, 2021).

\section{Conclusion}

The intensity of milk flow positively correlates with single milk yield, the milk flow rate in the first and second minutes of milking and maximum, the percentage of milk yield in the first and second minutes, the number of milk production cycles in two, three minutes and in general for milking. Negatively correlates the time of milk yield of the first 50 and $100 \mathrm{~g}$ of milk, the achievement of the maximum milk flow rate and the total milking time. The process of inhibition of milk flow weakens these connections. The type of HNA in cows influences the relationship of indicators of milk yield both under conditions of varying degrees of readiness for milk flow, and when exposed to the animals used in the experiment, conditioned and unconditioned stimuli.

\section{References}

1) Hemsworth PH, 2003. Human-animal interactions in livestock production. Applied Animal Behaviour Science 81:185-198

2) Kézér FL, Kovács L, Tőzsér J, 2015. Step behaviour and autonomic nervous system activity in multiparous dairy cows during milking in a herringbone milking system. Animal 9(8):1393-1396. doi: 10.1017/S1751731115000130

3) Marçal-Pedroza MG, Campos MM, Sacramento JP, Pereira LGR, Machado FS, Tomich TR, Paranhos da Costae MJR, Sant'Anna AC, 2021. Are dairy cows with a more reactive temperament less efficient in energetic metabolism and do they produce more enteric methane? Animal 15(6):100224. doi: 10.1016/j.animal.2021.100224

4) Marçal-Pedroza MG., Campos MM, Pereira LGR, Machado FS, Tomich TR, Paranhos da Costae MJR, Sant'Anna AC, 2020. Consistency of temperament traits and their relationships with milk yield in lactating primiparous F1 Holstein - Gyr cows. Applied Animal Behaviour Science 222:104881. doi: 10.1016/j.applanim.2019.104881

5) Mincu M, Gavojdian D, Nicolae I., Olteanu A., Vlagioiu C, 2021. Effects of milking temperament of dairy cows on production and reproduction efficiency under tied stall housing. Journal of Veterinary Behavior 44:12-17. doi: 10.1016/j.jveb.2021.05.010

6) Silva DC, Passini R, 2017. Physiological responses of dairy cows as a function of environment in holding pen. Scientific Paper, Agricultural Building and Environment. 37(02). doi: 10.1590/1809-4430-Eng.Agric.v37n2p206$214 / 2017$

7) Stephansen RS, Fogh A, Norberg E, 2018. Genetic parameters for handling and milking temperament in Danish firstparity Holstein cows. Journal of Dairy Science 101(12):11033-11039. doi: 10.3168/jds.2018-14804

8) Sutherland MA, Rogers AR, Verkerk GA, 2012. The effect of temperament and responsiveness towards humans on the behavior, physiology and milk production of multi-parous dairy cows in a familiar and novel milking environment. Physiology \& Behavior 107(3):329-337. doi: 10.1016/j.physbeh.2012.07.013

9) Vedovatto M, Faria FJC, Costa DS, Cooke RF, Sanchez JMD, Moriel P, Coelho RN, Franco GL, 2021. Effects of temperament on body parameters, ovarian structures and inflammatory response in grazing Nellore cows following fixed-time artificial insemination. Journal of Veterinary 44:50-54. doi: 10.1016/j.jveb.2021.03.005

10) Wenzel C, Schonreiter-Fischer S, Unshelm J, 2003. Studies on step-kick behavior and stress of cows during milking in an automatic milking system. Livestock Production Science 83(2-3):237-246. doi: 10.1016/S03016226(03)00109-X 